\title{
A REVIEW ON DETERMINING FACTORS FOR WOUND HEALING IN DIABETIC FOOT ULCERS
}

\author{
Melvin Ebin Bondi ${ }^{1}$, Syed Sharizman Syed Abdul Rahim ${ }^{2}$, Richard Avoi ${ }^{2}$, Firdaus Hayati ${ }^{3}$, \\ Azizan Omar',4, Sahipudin Saupin², Zulkhairul Naim Sidek Ahmad², Awang Setia Musleh², \\ Mohammad Saffree Jeffree ${ }^{2}$ \\ ${ }^{1}$ Non Communicable Disease Unit, Penampang Area Health Office, Penampang Sabah, Malaysia \\ ${ }^{2}$ Department of Community and Family Medicine, Universiti Malaysia Sabah, Kota Kinabalu, Sabah, \\ Malaysia \\ ${ }^{3}$ Department of Surgery, Universiti Malaysia Sabah, Kota Kinabalu, Sabah, Malaysia \\ ${ }^{4}$ Rural Medical Education Center, Faculty of Medicine and Health Sciences, Universiti Malaysia Sabah, \\ 89050 Kudat, Sabah, Malaysia
}

*Corresponding author: syedsharizman@ums.edu.my

\begin{abstract}
Diabetic Foot Ulcers (DFU) are significant complications of diabetes mellitus. DFU will often heal in a shorter period if factors that inhibit wound healing are identified and managed. This review was to identify determining factors that are associated with wound healing in DFU patients. Glycaemic control, adequate nutrition, presence of infection, the use of modern dressing approach, provide sufficient offloading and avoid unhealthy lifestyle like smoking are the highlighted determining factors discussed in this review and found to have an association towards a timely manner of wound healing in diabetic foot ulcers.
\end{abstract}

Keywords: determining factors, diabetic foot ulcer, wound healing, review. 


\section{Introduction}

Diabetic Foot Ulcers (DFUs) are significant complications of diabetes mellitus, which are linked with increase mortality, and reduce the quality of life which potentially life-threatening amputations (Sørensen, Jansen, Wilbek Fabricius, Jørgensen, \& Svendsen, 2019). For a lifetime prevalence of up to $25 \%$ in diabetes patients, foot ulcers are common and severe diabetes complications (Walsh, Hoffstad, Sullivan, \& Margolis, 2016). Because of the growing burden of diabetes ulcers, both to the patient and society, it is paramount to find relevant determining factors concerning diabetic foot ulcer wound healing. (Jeffcoate, Chipchase, Ince, \& Game, 2006)

About $2.7 \%$ of all hospitalized patients with diabetes mellitus have DFUs (Nussbaum et al., 2018; Zimny, Schatz, \& Pfohl, 2002). Although a lot of these patients might still have inadequate arterial blood flow to their limbs, it is at least in part caused by a loss of cutaneous sensation (peripheral insensitive neuropathy) (Walsh et al., 2016). Diabetes patients are unable to perceive sensations because of peripheral neuropathy which makes them vulnerable to trauma. (Grennan, 2019).

For wound healing of Diabetic Foot Ulcers with minimal to no complications, wound care management is essential (Broughton, Janis, \& Attinger, 2006). In four distinct and overlapping stages, wound healing is a complex sequence of interactions and reactions between cells and mediators, namely haemostasis, inflammation, fibroplasia, and maturation (AWC, MR, Helmy, \& Ramdhan, 2014). Diabetic Foot Ulcer involves several modes and multidisciplinary teamwork (Greenwell et al., 2018). Wound infection and non-healing Diabetic Foot Ulcers represent a hidden epidemic that affects a large fraction of the world's population and poses a huge and increasing challenge to public health and the economy (Ministry of Health Malaysia, 2018). Roughly 200,000 patients in the United Kingdom have infection-related non healing Diabetic Foot Ulcers. Treatment is estimated in the sum of 2.3 billion to 3.1 billion per year for patient with infected wound. (Harries, Bosanquet, \& Harding, 2016). This review aimed to highlight the determining factors of wound healing in diabetic foot ulcers and what impaired wound healing.

\section{Methods}

This narrative review included articles searched through PubMed and Google Scholar as a search engine to look for articles related to keywords of "determining factors", "wound healing" and "diabetic foot ulcers". Articles in these databases were from the year 2000 to 2019. A total of 50 eligible studies identified but only through the search. However, only 10 studies have met the inclusion criteria, whereas the other 35 studies were excluded in regard to duplicated and unrelated to the study criteria. 


\section{Determining factors of wound healing in diabetic foot ulcers}

\section{Haemoglobin A1c level in wound healing}

Haemoglobin A1c (HbA1c) is a reliable marker to monitor blood glucose in diabetic patients. HbA1c levels were associated with the process as well as the duration of wound healing in DFUs (Christman, Selvin, Margolis, Lazarus, \& Garza, 2011). Controlled HbA1c level of less than $6.5 \mathrm{mmol} / \mathrm{L}$ is linked to the acceleration of the duration of DFUs wound healing within three months ( $\mathrm{Li}$, Chen, \& Kirsner, 2007). However, an elevated HbA1c level (> $6.5 \mathrm{mmol} / \mathrm{L}$ )new cut off point for $\mathrm{HbA} 1 \mathrm{c}$ is $5.7 \mathrm{mmol} / \mathrm{L}$ is associated with poor prognosis and significantly delayed in wound healing of more than six months(Hasan et al., 2016). This is due to the inability of nutrients and oxygen to energize the cells. An uncontrolled level of sugar also prevents the immune system from functioning efficiently, which resulted in inflammation in the body cell, thus delayed in wound healing (Christman et al., 2011).

\section{Nutrition in Wound Healing}

The provision of nutritional care is proven to accelerate wound healing. Malnutrition or nutrient deficiencies can impair the maturation phase such as collagen synthesis prolong inflammation, dysfunction of $B$ and $T$ cells due to decrease in phagocytosis, as well as reduce in mechanical strength of the skin (Sajid, Miyan, Zaidi, Jaffri, \& Abdeali, 2018; Vas, Edmonds, \& Papanas, 2017). Optimal wound healing requires adequate nutrition as the process of healing demands increased consumption of energy to replace the injured tissue with new tissues (Guo \& DiPietro, 2010). However, ongoing monitoring is necessary to evaluate the outcome of nutrition intervention. The recommended intake for wound healing is as shown in table 1

Table 1: Recommended nutrients intake for wound healing in Diabetic Foot Ulcers patient

\begin{tabular}{|l|l|}
\hline Nutrients & Recommended Intake \\
\hline Energy & $30-45 \mathrm{kcal} / \mathrm{kg} /$ day \\
\hline Carbohydrate & $50-60 \%$ of energy \\
\hline Fat & $0.8-1.5 \mathrm{~g} / \mathrm{kg} /$ day \\
\hline Protein & $1.25 \mathrm{~g}-1.5 \mathrm{~g} / \mathrm{kg} /$ day \\
\hline Pharma co-nutrients & Omega-3 Fatty acid, Linoleic acid, L-Glutamine (0.2- \\
& $0.5 \mathrm{~g} / \mathrm{kg} /$ day), Arginine 30-60g/day \\
\hline Vitamins & Vitamin A, Vitamin B complex, Vitamin C, Vitamin E, \\
& Vitamin K, Zinc, Selenium, Manganese, Copper \\
\hline
\end{tabular}

Source: Ministry of Health Malaysia (2014) 


\section{Modern Dressing}

Wound care management using a modern dressing approach showed a significant change in wound healing of DFUs (BaMohammed et al., 2012). Selecting the appropriate wound care products on DFUs based on TIMES concept assessment (Tissue, Infection, Moisture Balance, Epithelialisation, and Skin Surrounding) by providing a well-vascularized, stable wound bed that is conducive to normal and timely healing (Dowsett, 2009; Finlayson et al., 2017). Modern dressing includes a selection of an appropriate solution, products, and technique of wound closure on the safety, preservation of function, and aesthetically pleasing outcome (Ministry of Health Malaysia, 2018).

\section{Diabetic Foot Infection}

Wound infection is found to hinder the wound contraction for both acute and chronic wounds (Gubara Musa \& Ahmed, 2012). The mechanism of which this occurs is assumed to be the release of bacterial enzymes and degrading of metalloproteinase fibrin and wound growth factors (Everett \& Mathioudakis, 2018). Aerobic gram-positive cocci, mainly Staphylococcus, are the most common pathogens that impair wound healing and increase the risk of gangrene, sepsis and bone infection like osteomyelitis. Early identification of the local and systemic infection is essential to prevent the worsening of the wound (Boulton, Kirsner, \& Vileikyte, 2004). The infection could be treated either with oral antibiotics, topical microbial agents, and parenteral antibiotics or surgical considerations (Raja, 2007). The selection of antibiotics is also paramount, especially patients with multidrug-resistant organisms, renal impairment, allergies, and immunosuppression (Zimny et al., 2002).

\section{Wound Size and Grading}

Wound size and grade impaired wound healing (Tsang et al., 2003). Various wound classification systems are used to describe the wound size and grade (S. Oyibo et al., 2001; Wong et al., 2015). The Wagner system is the one that commonly used to assess ulcer depth and the presence of osteomyelitis or gangrene by using the following grades; Grade 0 , grade 1 (partial/full-thickness ulcer), grade 2 (probing to tendon or capsule), grade 3 (deep with osteitis), grade 4 (partial foot gangrene), and grade 5 (whole foot gangrene) (S. Oyibo et al., 2001). Wound healing of DFU depends on the classifications, delayed wound healing is associated with the depth, size, and grade of the DFUs (Dinh, Elder, \& Veves, 2011).

\section{Smoking}

Smoking has been related to slow wound healing (Guo \& DiPietro, 2010) and insulin resistance (Gubara Musa \& Ahmed, 2012), especially in those smoking more than 10 packs/year (Guo \& DiPietro, 2010). Smoking is harmful and is associated with delaying the healing of diabetic foot ulcers (Gubara Musa \& Ahmed, 2012) and may help reduce the medical and economic burden on poor healing of diabetic foot (Guest, Fuller, \& Vowden, 2018). 


\section{Off-loading}

Off-loading is the most important healing factor in wound healing for diabetic foot ulcers (Boulton et al., 2004). The central goal of any treatment program designed to heal these wounds is effective off-loading (Guest et al., 2018). Structural abnormalities in a diabetic foot such as claw toe deformity and Charcot's neuroarthropathy are among the abnormalities that lead to significant disruption and elevate local foot pressures which resulted in the delay in wound healing (Bharat Kotru, 2015). Common off-loading methods include bed rest, wheelchair, crutch-assisted gait, total contact casts, felted foam and removable cast walkers (Cavanagh, Lipsky, Bradbury, \& Botek, 2005; Margolis, Kantor, Santanna, Strom, \& Berlin, 2000). Therapeutic shoes are designed to reduce the risk of skin breakdown (Walsh et al., 2016). Selection of shoes depends on numerous factors; how long someone has had diabetes, the presence of normal sensation on the feet, and if there are any abnormalities or deformities on the feet (O'Brien et al., 2003).

\section{Discussion}

There are numerous determining factors in the literature reviews associated with wound healing in DFUs. Despite, there was no standard criterion yet established to predict the prognosis of diabetic foot ulcer healing; however, this review revealed several determining factors that help influence the healing rate of diabetic foot ulcer. This review found that glycaemic control, such as HbA1c in the body shows the significant healing rate of DFUs (Gubara Musa \& E. Ahmed, 2012). Elevated glucose level due to compromised glycaemic control in the body results in impaired oxygen and nutrient supply (Falanga et al., 2017; Xiang et al., 2019) to the ulcer area and delayed the duration of healing (Finlayson et al., 2017). $\mathrm{HbA} 1 \mathrm{c}$ is a reliable marker of glycaemic control to diagnosis diabetes as recommended by the American Diabetes Association and by the World Health Organisation (WHO) (Manjunath \& Kumar, 2018).

Nutrition plays an essential role in the prevention and treatment of DFU, where an inadequate nutrient can result in altered immune function, malnutrition, and poor glycaemic control (Sajid et al., 2018). Nutrition is essential in healing which is also a substantial determining factor for accelerated healing rate (Vas et al., 2017). all repeated (Falanga et al., 2017; Rohmayanti \& Handayani, 2017). Patients with adequate nutrition and healthy body weight can help maximize wound healing due to obesity harms glycaemic control (Falanga et al., 2017).

Modern dressing plays a pivotal role in the management of diabetic foot ulcers, which comprises cleaning techniques and selection of the proper wound care products to provide a moist healing environment (Lindholm \& Searle, 2016). The modern dressing also comprises of topical treatment as well as bedside surgical management (debridement) and callous removal (Rohmayanti \& Handayani, 2017). In the advanced wound care management uses of vacuum aided devices, hyperbaric oxygen, and maggots help in accelerating wound healing (Margolis et al., 2000). 
The local ulcer characteristic, that is, depth and presence of skin callous had a significant effect on delayed wound healing (Oyibo et al., 2001). Serial debridement may increase the healing rate (Kavitha, 2014). A study by previously (Chaby et al., 2007) found that grade 4 and above classifications may impair speedy healing and often lead to amputation if not treated effectively. The presence of infection as such Staphylococcus Aureus may also delay the healing rate as compared to those non-infected DFU (Gubara Musa \& Ahmed, 2012).

Similarly, smoking is related to slow wound healing (Gubara Musa \& Ahmed, 2012) and insulin resistance. An accelerated wound healing can also be seen in non-smoker patients compared to a smoker (Guo \& DiPietro, 2010). Meanwhile, offloading is commonly recognized as a tremendous offloading modality in healing DFU (Cavanagh et al., 2005) and a substantial healing factor in DFU (Gubara Musa \& Ahmed, 2012). Around 75\% of DFU patients using off-loading had accelerated healing within six months to 1 year, while $25 \%$ did not heal for more than one year (Dinh et al., 2011).

Despite all the highlighted determining factors discussed in this study, a few other factors could influence the delay in wound healing of DFU. These are the factors that suggested to be explored in future research; the role of growth factors in wound healing wound debridement, ischaemia and distal sensory neuropathy, delays in seeking treatment, systemic medication, antineoplastic chemotherapy, tumours and environmental factors. The failure of these wounds to heal is also multifactorial. Therefore, treatment of DFU needs to be directed against main etiological factors responsible for the wound.

\section{Conclusion}

Diabetic foot ulcers remain a compelling burden despite the number of currently available treatment modalities. Numerous determining factors could influence the healing rate of DFU in a timely manner such as haemoglobin, nutrition, modern, presence of infection, classifications of DFU, smoking, and offloading. This review revealed that these factors should be taken into considerations when managing DFU. As a result, future wound care management should be aimed at addressing these challenging deficiencies in the hope to accelerate the healing rate of DFU. However, this review did not further investigate the other confounding or determining factors that impair wound healing at every wound healing stage.

\section{Conflicts of Interest:}

The authors declare no conflicts of interest. 


\section{References}

- AWC, L., MR, Z., Helmy, H., \& Ramdhan, I. (2014). Economic Impact of Managing Acute Diabetic Foot Infection in a Tertiary Hospital in Malaysia. Malaysian Orthopaedic Journal, 8(1), 46-49. https://doi.org/10.5704/moj.1403.018

- BaMohammed, A., Malaysia, M. of H., Catton, H., Geoghegan, L., Goss, A. J., Adami, R. Z., ... M B, S. (2012). Effects of skin care education for care staff at elderly care facilities on skin conditions of the residents. Diabetes Care, 12(3), 1-6. https://doi.org/10.1155/2014/126748

- Bharat Kotru, S. K. (2015). Intervention of Diabetes Foot Care Practices on the Prevention of New Diabetic Foot Ulcers in Patients with Type 2 Diabetes Mellitus. Journal of Diabetes \& Metabolism, 06(02). https://doi.org/10.4172/2155-6156.1000494

- Boulton, A. J. M., Kirsner, R. S., \& Vileikyte, L. (2004). Neuropathic Diabetic Foot Ulcers. New England Journal of Medicine, 351(16), 1694-1695. https://doi.org/10.1056/nejm200410143511626

- Broughton, G., Janis, J. E., \& Attinger, C. E. (2006). A brief history of wound care. Plastic and Reconstructive Surgery, $117(7 \quad$ SUPPL.), https://doi.org/10.1097/01.prs.0000225429.76355.dd

- Cavanagh, P. R., Lipsky, B. A., Bradbury, A. W., \& Botek, G. (2005). Treatment for diabetic foot ulcers. Lancet, 366(9498), 1725-1735. https://doi.org/10.1016/S0140-6736(05)67699-4

- Chaby, G., Senet, P., Vaneau, M., Martel, P., Guillaume, J. C., Meaume, S., ... Chosidow, O. (2007). Dressings for acute and chronic wounds: A systematic review. Archives of Dermatology, 143(10), 1297-1304. https://doi.org/10.1001/archderm.143.10.1297

- Christman, A. L., Selvin, E., Margolis, D. J., Lazarus, G. S., \& Garza, L. A. (2011). Hemoglobin A1C predicts healing rate in diabetic wounds. Journal of Investigative Dermatology, 131(10), 2121-2127. https://doi.org/10.1038/jid.2011.176

- Dinh, T., Elder, S., \& Veves, A. (2011). Delayed wound healing in diabetes: considering future treatments. Diabetes Management, 1(5), 509-519. https://doi.org/10.2217/dmt.11.44

- Dowsett, C. (2009). Use of TIME to improve community nurses' wound care knowledge and practice. Wounds UK, 5(3), 14-21.

- Everett, E., \& Mathioudakis, N. (2018). Update on management of diabetic foot ulcers. Annals of the New York Academy of Sciences, Vol. 1411. https://doi.org/10.1111/nyas.13569

- Falanga, V., Zimny, S., Schatz, H., Pfohl, M., Sørensen, M. L. B., Jansen, R. B., ... E. Ahmed, M. (2017). Determinants and estimation of healing times in diabetic foot ulcers. Lancet, 366(1), 327-332. https://doi.org/https://doi.org/10.1016/S1056-8727(01)00217-3

- Finlayson, K., Miaskowski, C., Alexander, K., Liu, W. H., Aouizerat, B., Parker, C., ... Edwards, H. (2017). Distinct Wound Healing and Quality-of-Life Outcomes in Subgroups of Patients With Venous Leg Ulcers With Different Symptom Cluster Experiences. Journal of Pain and Symptom Management, 53(5). https://doi.org/10.1016/j.jpainsymman.2016.12.336

- Greenwell, K., Sivyer, K., Vedhara, K., Yardley, L., Game, F., Chalder, T., ... Bradbury, K. (2018). Intervention planning for the REDUCE maintenance intervention: A digital intervention to reduce reulceration risk among patients with a history of diabetic foot ulcers. BMJ Open, 8(5), 1-12. https://doi.org/10.1136/bmjopen-2017-019865

- Grennan, D. (2019). Diabetic Foot Ulcers. JAMA - Journal of the American Medical Association, 321(1), 114. https://doi.org/10.1001/jama.2018.18323

- Gubara Musa, H., \& E. Ahmed, M. (2012). Associated risk factors and management of chronic diabetic foot ulcers exceeding 6 months' duration. Diabetic Foot \& Ankle, 3(1), 18980. https://doi.org/10.3402/dfa.v3i0.18980

- Guest, J. F., Fuller, G. W., \& Vowden, P. (2018). Diabetic foot ulcer management in clinical practice in the UK: costs and outcomes. International Wound Journal, 15(1). https://doi.org/10.1111/iwj.12816

- Guo, S., \& DiPietro, L. A. (2010). Critical review in oral biology \& medicine: Factors affecting wound healing. Journal of Dental Research, 89(3), 219-229. https://doi.org/10.1177/0022034509359125

- Harries, R. L., Bosanquet, D. C., \& Harding, K. G. (2016). Wound bed preparation: TIME for an update. International Wound Journal, 13, 8-14. https://doi.org/10.1111/iwj.12662

- Hasan, R., Firwana, B., Elraiyah, T., Domecq, J. P., Prutsky, G., Nabhan, M., ... Murad, M. H. (2016). A systematic review and meta-analysis of glycemic control for the prevention of diabetic foot syndrome. Journal of Vascular Surgery, 63(2), 22S-28S.e2. https://doi.org/10.1016/j.jvs.2015.10.005 
- Jeffcoate, W. J., Chipchase, S. Y., Ince, P., \& Game, F. L. (2006). Assessing the outcome of the management of diabetic foot ulcers using ulcer-related and person-related measures. Diabetes Care, 29(8), 1784-1787. https://doi.org/10.2337/dc06-0306

- Kavitha, K. V. (2014). Choice of wound care in diabetic foot ulcer: A practical approach. World Journal of Diabetes, 5(4), 546. https://doi.org/10.4239/wjd.v5.i4.546

- Li, J., Chen, J., \& Kirsner, R. (2007). Pathophysiology of acute wound healing. Clinics in Dermatology, 25(1), 9-18. https://doi.org/10.1016/j.clindermatol.2006.09.007

- Lindholm, C., \& Searle, R. (2016). Wound management for the 21st century: combining effectiveness and efficiency. International Wound Journal, 13. https://doi.org/10.1111/iwj.12623

- Manjunath, H. R., \& Kumar, V. M. (2018). Role of Hemoglobin A1c as Predictor of Foot Ulcer Healing in Diabetes. 4(2), 71-75. https://doi.org/10.17354/SUR/2018/149

- Margolis, D. J., Kantor, J., Santanna, J., Strom, B. L., \& Berlin, J. A. (2000). Risk factors for delayed healing of neuropathic diabetic foot ulcers: A pooled analysis. Archives of Dermatology, 136(12), 1531-1535. https://doi.org/10.1001/archderm.136.12.1531

- Ministry of Health Malaysia. (2018a). Clinical Practice Guidelines on Diabetic Foot Care (Vol. 18). https://doi.org/10.17226/1626

- Ministry of Health Malaysia. (2018b). Management of Diabetic Foot (Second Edition).

- Nussbaum, S. R., Carter, M. J., Fife, C. E., DaVanzo, J., Haught, R., Nusgart, M., \& Cartwright, D. (2018). An Economic Evaluation of the Impact, Cost, and Medicare Policy Implications of Chronic Nonhealing Wounds. Value in Health, 21(1). https://doi.org/10.1016/j.jval.2017.07.007

- O'Brien, K. E., Chandramohan, V., Nelson, D. A., Fischer, J. R., Stevens, G., \& Poremba, J. A. (2003). Effect of a physician-directed educational campaign on performance of proper diabetic foot exams in an outpatient setting. Journal of General Internal Medicine, 18(4), 258-265. https://doi.org/10.1046/j.1525-1497.2003.10662.x

- Oyibo, S., Jude, E., Tarawneh, I., Nguyen, H., Harkless, L., \& Baulton, E. (2001). A Comparison of Two Diabetic Foot Ulcer Classification Systems. Diabetes Care, 24(1), 84-88. https://doi.org/10.2337/diacare.24.1.84

- Oyibo, S. O., Jude, E. B., Tarawneh, I., Nguyen, H. C., Armstrong, D. G., Harkless, L. B., \& Boulton, A. J. M. (2001). The effects of ulcer size and site, patient's age, sex and type and duration of diabetes on the outcome of diabetic foot ulcers. Diabetic Medicine, 18(2), 133-138. https://doi.org/10.1046/j.1464-5491.2001.00422.x

- Raja, N. S. (2007). Microbiology of diabetic foot infections in a teaching hospital in Malaysia: A retrospective study of 194 cases. Journal of Microbiology, Immunology and Infection, 40(1), 39-44.

- Rohmayanti, ., \& Handayani, E. (2017). Modern wound care application in diabetic wound management. International Journal of Research in Medical Sciences, 5(2), 702. https://doi.org/10.18203/2320-6012.ijrms20170178

- Sajid, N., Miyan, Z., Zaidi, S. I. H., Jaffri, S. S. A., \& Abdeali, M. (2018). Protein requirement and its intake in subjects with diabetic foot ulcers at a tertiary care hospital. Pakistan Journal of Medical Sciences, 34(4), 886-890. https://doi.org/10.12669/pjms.344.15399

- Sørensen, M. L. B., Jansen, R. B., Wilbek Fabricius, T., Jørgensen, B., \& Svendsen, O. L. (2019). Healing of Diabetic Foot Ulcers in Patients Treated at the Copenhagen Wound Healing Center in 1999/2000 and in 2011/2012. Journal of Diabetes Research, 2019. https://doi.org/10.1155/2019/6429575

- $\quad$ Tsang, M. W., Wong, W. K. R., Hung, C. S., Lai, K. M., Tang, W., Cheung, E. Y. N., ... Lam, E. K. H. (2003). Human epidermal growth factor enhances healing of diabetic foot ulcers. Diabetes Care, 26(6), 1856-1861. https://doi.org/10.2337/diacare.26.6.1856

- Vas, P. R. J., Edmonds, M. E., \& Papanas, N. (2017). Nutritional Supplementation for Diabetic Foot Ulcers: The Big Challenge. International Journal of Lower Extremity Wounds, 16(4), 226229. https://doi.org/10.1177/1534734617740254

- Walsh, J. W., Hoffstad, O. J., Sullivan, M. O., \& Margolis, D. J. (2016). Association of diabetic foot ulcer and death in a population-based cohort from the United Kingdom. Diabetic Medicine, 33(11). https://doi.org/10.1111/dme.13054

- Wong, S. L., Demers, M., Martinod, K., Gallant, M., Wang, Y., Goldfine, A. B., ... Wagner, D. D. (2015). Which Severely Impairs Wound Healing. Nature Medicine, 21(7), 1-9. https://doi.org/10.1038/nm.3887

- Xiang, J., Wang, S., He, Y., Xu, L., Zhang, S., \& Tang, Z. (2019). Reasonable Glycemic Control Would Help Wound Healing During the Treatment of Diabetic Foot Ulcers. Diabetes Therapy, 10(1), 95-105. https://doi.org/10.1007/s13300-018-0536-8 
- Zimny, S., Schatz, H., \& Pfohl, M. (2002). Determinants and estimation of healing times in diabetic foot ulcers. Journal of Diabetes and Its Complications, 16(5), 327-332. https://doi.org/https://doi.org/10.1016/S1056-8727(01)00217-3 